\title{
ERODIBILIDADE DE UM NITOSSOLO HÁPLICO ALUMÍNICO DETERMINADA EM CONDIÇÕES DE CAMPO(1)
}

\author{
Ildegardis Bertol $^{(2)}$, Dirceu Leite ${ }^{(3)}$, Fernando Luis Engel $^{(3)}$, Neroli \\ Pedro Cogo ${ }^{(4)}$ \& Antônio Paz González ${ }^{(5)}$
}

\begin{abstract}
RESUMO
O termo erodibilidade do solo (fator K na Equação Universal de Perda de Solo - EUPS) expressa a suscetibilidade natural do solo à erosão hídrica. $\mathrm{O}$ fator $\mathrm{K}$ representa a taxa de perda de solo por unidade de erosividade da chuva (fator $R$ na EUPS). O conhecimento do fator $\mathrm{K}$, juntamente com os demais fatores do modelo EUPS, é importante no planejamento conservacionista, pois, por meio desse modelo, estimam-se as perdas médias anuais de solo esperadas para determinadas condições. Dados de perda de solo, obtidos em campo em solo sem cultivo e com preparo convencional, sob condições de chuva simulada, no período de novembro de 2001 a março de 2004, no sul do Planalto Catarinense, foram utilizados para calcular o fator K de um Nitossolo Háplico alumínico típico, com declividade média de $0,15 \mathrm{~m} \mathrm{~m}^{-1}$. $\mathrm{O}$ fator $\mathrm{K}$ foi calculado pela razão entre as perdas de solo e a erosividade das chuvas e, ainda, estimado por análise de regressão linear simples entre estas duas variáveis. Foram utilizados valores de erosividade das chuvas $\left(\mathrm{EI}_{30}\right)$ de 11 testes de chuva simulada e suas respectivas perdas de solo, obtidas em parcelas de $3,5 \times 11,0 \mathrm{~m}$, desprovidas de vegetação e de crosta superficial, após terem sido mantidas sem cultivo e sob preparo de solo contínuo por dois anos. O preparo do solo, executado no sentido do declive, duas vezes ao ano, consistiu de uma aração e duas gradagens. A crosta superficial e as plantas espontâneas eram mecanicamente eliminadas por meio de escarificação e de capina manual com enxada. O fator erodibilidade do solo determinado para o Nitossolo Háplico alumínico foi de $0,011 \mathrm{Mg}$ ha h ha-1 $\mathrm{MJ}^{-1} \mathrm{~mm}^{-1}$ quando calculado por meio da razão entre os valores anuais de perda de solo e do índice de erosividade das chuvas e de $0,012 \mathrm{Mg}_{\text {ha }} \mathrm{h} \mathrm{ha}^{-1}$ $\mathrm{MJ}^{-1} \mathrm{~mm}^{-1}$ quando estimado por meio de regressão linear simples entre estas duas variáveis.
\end{abstract}

Termos de indexação: erosão hídrica, perda de solo, chuva simulada, fator K.

\footnotetext{
(1) Trabalho desenvolvido com recursos parciais do CNPq/CAV/CAPES. Recebido para publicação em dezembro de 2005 e aprovado em janeiro de 2007.

(2) Professor do Departamento de Solos do Centro de Ciências Agroveterinárias, Universidade do Estado de Santa Catarina CAV/UDESC. Caixa Postal 281, CEP 88520-000 Lages (SC), Brasil. Bolsista de pesquisa do CNPq. E-mail: a2ib@cav.udesc.br (3) Engenheiro-Agrônomo, MSc., CAV/UDESC. Lages (SC).

(4) Professor Adjunto do Departamento de Solos da Universidade Federal do Rio Grande do Sul - UFRGS. Caixa Postal 15100, CEP 91501-970 Porto Alegre (RS). Bolsista do CNPq. E-mail: neroli@ufrgs.br

(5) Professor da Faculdade de Ciências da UDC. Caixa Postal 15071, La Coruña, España. E-mail: tucho@udc.es
} 


\title{
SUMMARY: ERODIBILITY OF A TYPIC HAPLUDOX EVALUATED UNDER FIELD CONDITIONS
}

\begin{abstract}
The term soil erodibility (factor $K$ in the Universal Soil Loss Equation - USLE) expresses the natural susceptibility of a soil to water erosion. The $K$ factor stands for the soil loss rate per unit of rainfall erosivity (factor $R$ in the USLE). Knowledge on the $K$ factor, as well as about the other factors of the USLE, is important to establish soil conservation strategies since they permit the estimation of soil loss rates by water erosion under specific climate, soil, topography, and management conditions. Soil losses data from fallowed or continuously tilled plots, using simulated rainfall, were obtained in the period from November, 2001 to March, 2004, in the South of the Planalto Catarinense, Santa Catarina state, Brazil, and used to calculate the soil erodibility of an Hapludox with $0.15 \mathrm{~m} \mathrm{~m}^{-1}$ slope. The $K$ factor was calculated by the ratio of the soil losses by the rainfall erosivity values ( $E I_{30}$ index). It was also estimated through simple linear regression analysis based on the two variables. Eleven rainfall tests with the rotating-boom rainfall simulator were performed to obtain the necessary data for this study, using $3.5 \times 11.0 \mathrm{~m}$ plots that were maintained under continuous tillage or fallowed for two years before the rainfall tests began. The soil erodibility for this soil was determined at $0.011 \mathrm{Mg}$ ha h ha-1 $\mathrm{MJ}^{-1} \mathrm{~mm}^{-1}$ when calculated based on he soil losses/rainfall erosivity ratio and $0.012 \mathrm{Mg}$ ha h ha-1 $\mathrm{MJ}^{-1}$ $\mathrm{mm}^{-1}$ when estimated by simple linear regression.
\end{abstract}

Index terms: water erosion, soil loss, simulated rainfall, $K$ factor.

\section{INTRODUÇÃO}

A erosão hídrica é resultante da ação conjunta do impacto das gotas de chuva e da enxurrada sobre o solo, caracterizada pelas fases de desagregação, transporte e deposição. A desagregação e o transporte são principalmente provocados pelo impacto das gotas de chuva e pelo cisalhamento da enxurrada, respectivamente, sobre a superfície do solo (Hudson, 1995).

A erodibilidade do solo (fator $\mathrm{K}$ da Equação Universal de Perda de solo - EUPS) significa sua suscetibilidade natural à erosão hídrica, expressa como a quantidade de solo perdido por unidade de erosividade da chuva (fator R da EUPS), e, por isso, a unidade de expressão do fator $\mathrm{K}$ é $\mathrm{Mg}$ ha $\mathrm{h} \mathrm{ha}^{-1} \mathrm{MJ}^{-1} \mathrm{~mm}^{-1}$ (Wischmeier \& Smith, 1978). O fator erodibilidade é calculado por meio da razão entre as perdas de solo e a erosividade das chuvas (Wischmeier, 1959; Wischmeier \& Smith, 1978) ou, ainda, estimado por meio de análise de regressão linear simples entre estas duas variáveis (Wischmeier \& Mannering, 1969). Para que a erodibilidade possa ser estimada por regressão, é necessário que os dados de perda de solo tenham sido obtidos em campo, diretamente da parcela "padrão" da EUPS. Dados de perda de solo coletados em parcela experimental com declividade e, ou, comprimento de rampa diferentes daqueles da parcela "padrão" devem ser ajustados para a condição "padrão", como proposto por Wischmeier \& Smith $(1958,1978)$.

Os valores de erodibilidade do solo são utilizados, entre outros aspectos, para estabelecer uma escala de suscetibilidade natural dos solos à erosão hídrica.
Foster et al. (1981) sugeriram os valores de 0,010, 0,030 e $0,060 \mathrm{Mg}$ ha h ha-1 $\mathrm{MJ}^{-1} \mathrm{~mm}^{-1}$ para classificar a erodibilidade dos solos americanos como sendo de erodibilidade baixa, moderada e alta, respectivamente. Assim, solos de baixa erodibilidade, por exemplo, apresentam alta resistência natural à erosão hídrica.

A erodibilidade do solo apresenta grande variabilidade espacial e temporal, a qual é parcialmente explicada pela variabilidade climática que influi no potencial erosivo das chuvas, pelo teor de água do solo antecedente às chuvas e pela variabilidade do solo que influencia a suscetibilidade deste à erosão (Römkens et al., 1977; Mutchler \& Carter, 1983; Liebenow et al., 1990). No Brasil, uma série de trabalhos tem sido conduzida, em campo, sob chuva natural em parcelas experimentais com dimensões de 3,5 x 22,1 m (Martins Filho \& Silva, 1985; Margolis et al., 1985; Silva et al., 1997; Carvalho et al., 1997; Marques et al., 1997; Beutler, 2000; Carvalho \& Hernani, 2001; Bertol et al., 2002) e sob chuva simulada em parcelas com dimensões de 3,5 x 11,0 m (Denardin \& Wünsche, 1980; Martins Filho \& Silva, 1985; Távora et al., 1985), para calcular e estimar, por vários métodos, a erodibilidade de solos nacionais. Nos referidos trabalhos, constata-se grande variação de valores de fator $\mathrm{K}$, dependendo do tipo de solo, da condição climática característica de cada local e do método de obtenção.

Denardin \& Wünsche (1980), trabalhando sob chuva simulada em um Latossolo Vermelho distrófico típico, em Passo Fundo, RS, obtiveram o fator K de $0,021 \mathrm{Mg}$ ha h ha-1 $\mathrm{MJ}^{-1} \mathrm{~mm}^{-1}$; Martins Filho \& Silva (1985), em um Latossolo Vermelho-Amarelo distrófico, 
em Jaboticabal, SP, sob chuva natural e simulada, obtiveram fatores $\mathrm{K}$ praticamente iguais a este; e, neste mesmo local e solo, Martins Filho \& Pereira (1993) determinaram o fator K de 0,009. Utilizando as equações de energia cinética propostas por Wischmeier \& Smith (1958) e por Wagner \& Massambani (1988), respectivamente, para um Latossolo Vermelho-Escuro textura média, em Paranavaí, PR, Jacobs et al. (1994) constataram, sob chuva natural, fatores $\mathrm{K}$ de $0,008 \mathrm{Mg}$ ha h ha-1 $\mathrm{MJ}^{-1}$ $\mathrm{mm}^{-1}$; para um Latossolo Vermelho distrófico típico, em Ponta Grossa, PR, os mesmos autores obtiveram, ainda sob chuva natural, fatores $\mathrm{K}$ de 0,008 , utilizando as mesmas equações anteriormente referidas. Marques et al. (1997), sob chuva natural, obtiveram fator $\mathrm{K}$ de $0,002 \mathrm{Mg}$ ha h ha-1 $\mathrm{MJ}^{-1} \mathrm{~mm}^{-1}$ para um Latossolo Vermelho distrófico típico, em Sete Lagoas, MG, enquanto Beutler (2000), trabalhando num Latossolo Vermelho aluminoférrico típico, em Chapecó, SC, obteve sob chuva natural o valor de $\mathrm{K}$ de 0,021 . A variabilidade dos valores de fator K para os Latossolos, recém-referida, é decorrente da variabilidade climática entre os locais, da variação das propriedades dos solos e da distinção no modo de obtenção.

Para um Argissolo Vermelho-Amarelo alumínico típico, em Sete Lagoas, MG, Marques et al. (1997) obtiveram, sob chuva natural, fator K de 0,033, expressivamente maior do que os valores determinados em Latossolos, decorrente das diferenças entre as duas classes de solo, em especial a textura, mineralogia, profundidade do perfil e constituição dos horizontes.

Bertol (1994) e Schick (1999), trabalhando com dados de três e seis anos de um Cambissolo Húmico alumínico léptico, em Lages, SC, obtiveram, sob chuva natural, valores de fator $\mathrm{K}$ de 0,016 e 0,013, respectivamente. Para o mesmo solo e local, Bertol et al. (2002) obtiveram o fator K médio anual de 0,012, calculado pela razão entre as perdas de solo e a erosividade das chuvas. Nesse mesmo trabalho e calculado do mesmo modo, estes autores obtiveram o fator $\mathrm{K}$ de 0,011 para o período de primavera-verão e de 0,013 para o outono-inverno. Trabalhando com os dados em base anual e utilizando regressão linear simples, Bertol et al. (2002) estimaram o fator K igual a 0,015 $\mathrm{e}$, com os dados estacionais, obtiveram valores de $\mathrm{K}$ de 0,012 para o período de primavera-verão e de 0,023 para o outono-inverno. Os valores de K neste Cambissolo podem ser considerados relativamente baixos, se comparados aos dos Latossolos e, principalmente, ao do Argissolo, explicado principalmente pelo elevado teor de matéria orgânica do Cambisolo e, ainda, pela erosividade relativamente elevada do local.

O objetivo deste trabalho foi determinar o fator erodibilidade do solo por meio do quociente entre os valores anuais de perda de solo e os de erosividade de 11 chuvas simuladas, bem como estimar a erodibilidade, por meio de regressão linear simples entre os dados dessas duas variáveis, de um Nitossolo Háplico alumínico.

\section{MATERIAL E MÉTODOS}

A presente pesquisa foi conduzida sob condições de chuva simulada, em campo, em um Nitossolo Háplico alumínico textura argilosa, localizado no Colégio Agrícola Caetano Costa, no município de São José do Cerrito, Planalto Sul Catarinense, situado entre $28^{\circ} 55$ ' de latitude sul e $51^{\circ} 08$ ' de longitude oeste de Greenwich, no período de novembro de 2001 a março de 2004. A altitude média no local do experimento é de $846 \mathrm{~m}$ e, segundo Köppen, o clima da região é do tipo $\mathrm{Cfb}$. Os principais atributos do solo, no local das parcelas experimentais, estão descritos no quadro 1.

Foi instalado um tratamento de preparo do solo, em duas repetições, em parcelas experimentais de $3,5 \times 11,0 \mathrm{~m}$, as quais, na média, apresentavam declividade de $0,15 \mathrm{~m} \mathrm{~m}^{-1}$. O solo nas parcelas era preparado duas vezes por ano (na primavera-verão e no outono-inverno), com uma aração na profundidade de 0,20 m, usando arado de discos, seguida de duas gradagens na profundidade de $0,15 \mathrm{~m}$, utilizando grade de discos destorroadora. Além disso, a superfície do solo era mantida livre de vegetação e de crosta superficial, por meio de capinas e escarificações manuais, efetuadas sempre que necessário. As referidas parcelas foram delimitadas por chapas galvanizadas nas laterais e na extremidade superior e por calhas coletoras de enxurrada na sua extremidade inferior, as quais eram conectadas a canos de PVC que conduziam a enxurrada até os pontos de coleta, situados 6,0 $\mathrm{m}$ abaixo das parcelas.

Nas parcelas experimentais foram aplicados 11 testes de chuva simulada, entre novembro de 2001 e março de 2004. O primeiro foi aplicado em 5/11/ 2001 e os dois seguintes, em intervalos de aproximadamente 45 dias um do outro. O quarto teste foi aplicado em 15/11/2002 e, os dois seguintes, em intervalos de aproximadamente 30 dias um do outro. Em 12/11/2003 aplicou-se o sétimo teste de chuva, e os demais, em intervalos de aproximadamente 30 dias um do outro, até completar o décimo primeiro teste, em março de 2004. O primeiro, o quarto e o sétimo testes foram aplicados imediatamente após as operações de preparo do solo anteriormente descritas. Utilizou-se um aparelho simulador de chuvas de braços rotativos tipo Swanson (Swanson, 1975) para aplicar as chuvas simuladas, as quais foram planejadas para a intensidade de $64 \mathrm{~mm} \mathrm{~h}^{-1}$. No entanto, a intensidade das chuvas aplicadas variou, entre chuvas, em relação à planejada. As chuvas tiveram duração suficiente para tornar a enxurrada constante por um período de 30 min. Em decorrência da variação de intensidade e duração, as alturas de chuva também variaram entre si.

A coleta das amostras de enxurrada, feita a cada três minutos durante o período de sua ocorrência e seu processamento em laboratório para posterior cálculo das perdas de solo, realizou-se de acordo com o método descrito em Cogo (1981) e Bertol et al. (2006). 
Quadro 1. Atributos do solo nos diferentes horizontes de um Nitossolo Háplico alumínico

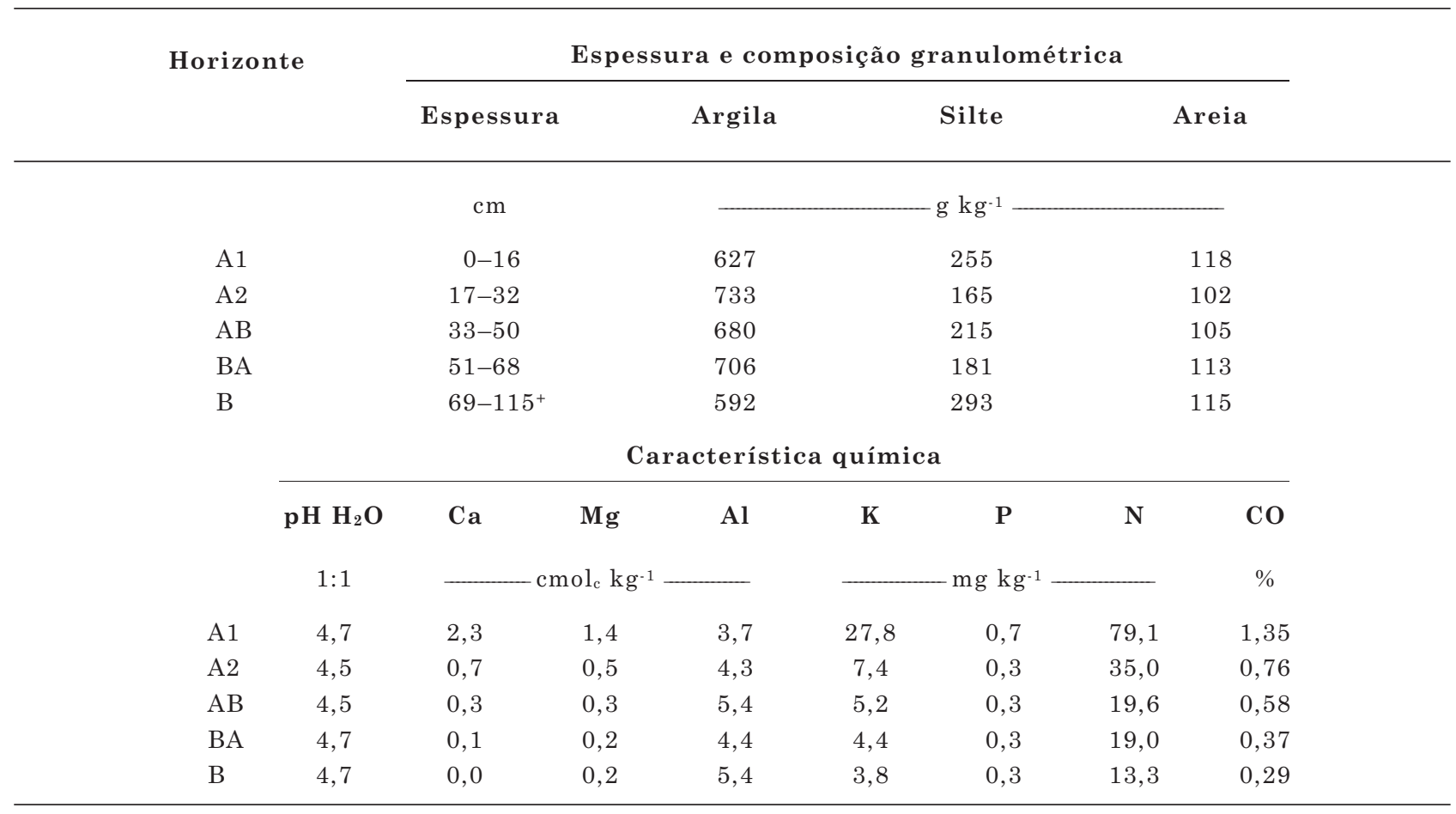

Os dados de perda de solo foram ajustados para a intensidade de chuva planejada de $64 \mathrm{~mm} \mathrm{~h}^{-1}$, devido à diferença de intensidade entre as chuvas aplicadas e a chuva planejada, conforme método descrito em Cogo (1981), resumidamente descrito a seguir: a perda total de solo ajustada foi obtida dividindo-se a intensidade de chuva planejada pela intensidade de chuva observada, elevando-se esse valor ao quadrado e multiplicando o resultado pela perda de solo observada. Após o ajuste para a intensidade de chuva, os dados de perda de solo foram também ajustados para a declividade de $0,09 \mathrm{~m} \mathrm{~m}^{-1}$, por meio do fator grau do declive, conforme proposto por Wischmeier \& Smith (1978), utilizando a equação:

$$
\mathrm{S}=0,065+4,56 \operatorname{sen} \mathrm{q}+65,41(\operatorname{sen} \theta)^{2}
$$

em que $\mathrm{S}=$ fator grau do declive (adimensional); e $\theta=$ ângulo do declive (adimensional).

Após ajuste dos dados de perda de solo para a declividade, eles foram ainda ajustados para o comprimento da parcela experimental "padrão" da EUPS, de $22,1 \mathrm{~m}$, por meio do fator comprimento do declive, conforme proposto por Wischmeier \& Smith (1978), utilizando a equação:

$$
\mathrm{L}=\left(\lambda / \lambda_{\mathrm{n}}\right)^{\mathrm{m}}
$$

em que $\mathrm{L}=$ fator comprimento do declive (adimensional); $\lambda=$ comprimento da parcela experimental "padrão", para ser utilizado com chuva simulada, no campo $(11,0 \mathrm{~m}) ; \lambda_{\mathrm{n}}=$ comprimento da parcela experimental "padrão", para ser usado com chuva natural, no campo $(22,1 \mathrm{~m})$; e $\mathrm{m}=$ expoente que varia conforme o grau do declive, o qual, neste caso, é igual a 0,5, já que a declividade média das parcelas experimentais, no campo $\left(0,15 \mathrm{~m} \mathrm{~m}^{-1}\right)$, era maior do que $0,05 \mathrm{~m} \mathrm{~m}^{-1}$.

$\mathrm{O}$ fator erosividade $\left(\mathrm{EI}_{30}\right)$ das 11 chuvas simuladas foi calculado conforme método descrito em Meyer (1958), utilizando a seguinte equação expressa no Sistema Internacional de Unidades:

$$
\mathrm{EI}_{30}=0,2083 \mathrm{Q} \mathrm{I}_{30}
$$

em que $0,2083=$ energia cinética para um milímetro de chuva simulada; $\mathrm{Q}=$ altura total da chuva simulada, $\mathrm{mm}$; e $\mathrm{I}_{30}$ = intensidade máxima da chuva simulada em 30 min, a qual, neste caso, era igual à intensidade das chuvas, já que estas apresentavam intensidade constante, $\mathrm{mm} \mathrm{h}^{-1}$.

$\mathrm{O}$ fator erodibilidade do solo (fator $\mathrm{K}$ - Mg ha h ha-1 $\mathrm{MJ}^{-1} \mathrm{~mm}^{-1}$ ) foi determinado utilizando os dados de perda de solo resultantes das 11 chuvas simuladas. $\mathrm{O}$ fator $\mathrm{K}$ foi calculado por meio da razão entre os valores médios de perda de solo $\left(\mathrm{Mg} \mathrm{ha}^{-1}\right)$ e de erosividade das chuvas (MJ mm ha-1 $\mathrm{h}^{-1}$ ), seguindo o procedimento de Wischmeier \& Smith (1978). Ainda, o fator erodibilidade foi estimado por análise de regressão linear simples, por meio do modelo $Y=a+$ $b X$, em que Yrepresenta os valores de perda de solo e $\mathrm{X}$ os de erosividade das chuvas, seguindo o procedimento de Wischmeier \& Mannering (1969). 
Nesse caso, o fator erodibilidade do solo é representado pela constante $b$, a qual determina a inclinação da reta, respeitando-se o grau de ajuste indicado pelo coeficiente de determinação, $\mathrm{R}^{2}$. Embora a regressão linear não tenha resultado no melhor ajuste para os pares de pontos de perdas de solo e de erosividade, em comparação com a função não-linear, a linear foi preferida pelo fato de ser ela consagrada pelo procedimento adotado por Wischmeier \& Mannering (1969).

Procedimentos de estatística básica foram utilizados para calcular a média, o desvio-padrão, o coeficiente de variação e os limites inferior e superior em relação à média no intervalo de confiança de $95 \%$ dos dados.

\section{RESULTADOS E DISCUSSÃO}

A intensidade das chuvas simuladas aplicadas situou-se próximo da média de $64,1 \mathrm{~mm} \mathrm{~h}^{-1}$ (Quadro 2), ou seja, praticamente igual à intensidade de chuva planejada de $64 \mathrm{~mm} \mathrm{~h}^{-1}$. As chuvas 3 e 6 e as 4 e 5 situaram-se fora do intervalo de confiança de $95 \%$, com intensidade acima e abaixo da média, respectivamente. A variação na intensidade das chuvas simuladas, em relação à média, influenciou parcialmente as perdas de solo usadas no cálculo e na estimativa da erodibilidade, embora as referidas perdas tenham sido ajustadas para a intensidade de chuva planejada, conforme verificado também por Wischmeier \& Smith (1978) e Liebenow et al. (1990).

Em relação à altura das chuvas, o desvio-padrão foi mais expressivo do que ocorreu com a intensidade (Quadro 2). As menores alturas ocorreram nas chuvas de número 2 e 4 e, as maiores, nas de número 6 e 11, levando-se em conta o intervalo de confiança de $95 \%$. Assim, a altura das chuvas simuladas aplicadas, associada à intensidade delas, influenciou consideravelmente os valores de erosividade e, portanto, os de perdas de solo e os de erodibilidade. Contribuiu para a variabilidade das perdas de solo o fato de que os dados dessa variável não foram ajustados para a altura de chuva, como fora feito para a intensidade.

Do mesmo modo que a intensidade e a altura, a duração das chuvas simuladas variou, situando-se, em média, em 80 min (Quadro 2). A duração das chuvas é uma característica intrínseca e, por isso mesmo, complementar à intensidade e à altura destas; por esse motivo, sua variação certamente influenciou os valores de erosividade, perdas de solo e erodibilidade.

A variação no teor de água do solo antecedente às 11 chuvas simuladas foi pequena, ou seja, de $0,01 \mathrm{~g} \mathrm{~g}^{-1}$ para baixo e para cima em relação ao teor médio (Quadro 2). A pequena variação do teor de água no solo pouco influenciou as variações de tempos de início e de pico da enxurrada e, conseqüentemente, as variações de perda de solo e de erodibilidade. A diferença entre os teores mínimo e máximo de água do solo foi de $0,04 \mathrm{~g} \mathrm{~g}^{-1}$, ou seja, de $15 \%$, enquanto a diferença entre as perdas mínima e máxima de solo foi de $14,2 \mathrm{Mg} \mathrm{ha}^{-1}$, ou de $236 \%$. Essa pequena influência do teor de água do solo antecedente às chuvas nas perdas de solo provavelmente se deveu ao fato de que as chuvas simuladas foram aplicadas sempre imediatamente após a execução do preparo do solo. Para efetivação do preparo, procurou-se observar o teor adequado de água do solo para tal, ou seja, ver se este era equivalente ao ponto de friabilidade. Assim, a variação das perdas de solo deve ter sido influenciada mais fortemente pela variação de outros atributos que não a variação do teor de água.

Os tempos necessários para iniciar a enxurrada e para esta atingir sua vazão máxima apresentaram variações pequenas em relação à média (Quadro 2), comparadas à magnitude das durações das chuvas.

Quadro 2. Intensidade (i, $\left.\mathrm{mm} \mathrm{h}^{-1}\right)$, altura (p, $\mathrm{mm}$ ) e duração (d, min) das chuvas simuladas, teor de água no solo antecedente às chuvas (ug, $\mathrm{g} \mathrm{g}^{-1}$ ) e tempos de início (ti, min) e de vazão máxima (tq, min) da enxurrada, em um Nitossolo Háplico alumínico

\begin{tabular}{|c|c|c|c|c|c|c|c|c|c|c|c|c|c|c|c|}
\hline \multirow{2}{*}{ Variável } & \multicolumn{11}{|c|}{ Teste de chuva - no } & \multicolumn{4}{|c|}{ Parâmetro estatístico } \\
\hline & 1 & 2 & 3 & 4 & 5 & 6 & 7 & 8 & 9 & 10 & 11 & M & DP & $\mathbf{L I}$ & LS \\
\hline $\mathrm{i}$ & 61,3 & 63,1 & 72,6 & 58,8 & 61,4 & 66,6 & 64,1 & 65,4 & 65,1 & 64,1 & 63,0 & 64,1 & 3,4 & 61,8 & 66,4 \\
\hline $\mathrm{p}$ & 82,8 & 63,1 & 90,8 & 60,8 & 92,2 & 99,9 & 85,3 & 83,2 & 90,7 & 93,8 & 96,0 & 85,3 & 12,1 & 77,2 & 93,4 \\
\hline$d$ & 81 & 60 & 75 & 62 & 90 & 90 & 80 & 76 & 84 & 88 & 91 & 80 & 10 & 73 & 87 \\
\hline ug & 0,29 & 0,30 & 0,29 & 0,30 & 0,27 & 0,26 & 0,26 & 0,26 & 0,26 & 0,26 & 0,26 & 0,27 & 0,02 & 0,26 & 0,28 \\
\hline $\mathrm{ti}$ & 23 & 19 & 24 & 22 & 19 & 22 & 19 & 18 & 19 & 18 & 19 & 20 & 2 & 19 & 21 \\
\hline $\operatorname{tq}$ & 56 & 40 & 52 & 40 & 59 & 45 & 52 & 48 & 57 & 55 & 57 & 51 & 7 & 46 & 56 \\
\hline
\end{tabular}

M: média; DP: desvio-padrão; LI e LS: limites inferior e superior em relação à média no intervalo de confiança de $95 \%$. 
A diferença no tempo de início da enxurrada foi de $33 \%$ entre o menor e o maior valor, enquanto a diferença no tempo para a enxurrada atingir o pico foi de $48 \%$ entre o menor e o maior valor. A variação nos tempos de início e de pico da enxurrada foi maior do que a ocorrida nos teores de água do solo, sendo explicada por prováveis diferenças nas características de superfície do solo presentes após o preparo efetuado nas diversas oportunidades. Embora tenha sido efetuado o mesmo tipo de preparo do solo (uma aração seguida de duas gradagens), antecedendo as chuvas simuladas aplicadas, ele resultou em diferentes características superficiais em cada caso, principalmente rugosidade, pulverização, porosidade e volume de solo mobilizado. A variação dessas características é absolutamente normal, tendo sido observada neste trabalho e também por Cogo (1981) e Bertol (1995). Isso influenciou os tempos de início e pico da enxurrada, os quais tiveram influência sobre as perdas de solo e sua erodibilidade em magnitude maior do que teve a variação do teor de água do solo antecedente às chuvas.

O fator erodibilidade do solo, obtido pela razão entre as perdas de solo e a erosividade das chuvas, variou expressivamente no período estudado, com média de $0,011 \mathrm{Mg}$ ha h ha-1 $\mathrm{MJ}^{-1} \mathrm{~mm}^{-1}$ e DP de 0,003 (Quadro 3). O menor valor ocorreu na chuva de número 4, aplicada em novembro de 2002 , na qual os valores de características das chuvas, teor de água no solo antecedente às chuvas e tempos de início e pico da enxurrada situaram-se fora dos intervalos das médias (Quadro 2). O maior valor de erodibilidade ocorreu na chuva de número 6 , aplicada em março de 2003, com diferença de aproximadamente duas vezes em relação ao menor valor, embora a erosividade tenha sido apenas 1,6 vez maior na chuva de número 6 . Isso ocasionou perda de solo aproximadamente 3,2 vezes maior na chuva de número 6 do que na de número 4 , explicada principalmente pela altura de chuva $-64 \%$ maior na chuva de número 6 do que na de número 4 . Nesse caso, a altura de chuva foi o principal fator determinante da diferença de erosividade e da diferença de perda de solo, já que a intensidade (planejada) era igual em ambos os casos. A duração das chuvas também influenciou esse comportamento, já que esta variável se refletiu na altura de chuva (Quadro 2), ao passo que o teor de água do solo antecedente às chuvas, pouco variável, influenciou apenas levemente as perdas de solo e sua erodibilidade.

A variação temporal da perda de solo (39 \%) foi expressivamente maior do que a da erosividade das chuvas (15\%), refletindo-se parcialmente na erodibilidade do solo, que variou $29 \%$ (Quadro 3). O valor médio do fator $\mathrm{K}$ foi de $0,011 \mathrm{Mg}$ ha h ha-1 $\mathrm{MJ}^{-1}$

Quadro 3. Data de aplicação das chuvas simuladas, altura total (p) e erosividade (EI ( $_{30}$ ) das chuvas, perda de solo (PS) ajustada para a intensidade de chuva planejada de $64 \mathrm{~mm} \mathrm{~h}^{-1}$, para a declividade do solo de $0,09 \mathrm{~m} \mathrm{~m}^{-1}$ e para o comprimento do declive de $22,1 \mathrm{~m}$, e fator erodibilidade do solo (fator K) do Nitossolo Háplico alumínico

\begin{tabular}{|c|c|c|c|c|c|}
\hline Chuva & Data da chuva & $\mathbf{P}$ & $\mathbf{E I}_{30}$ & $\mathbf{P S}$ & Fator $\mathbf{K}$ \\
\hline No & & $\mathrm{mm}$ & MJ mm ha-1 $\mathrm{h}^{-1}$ & $\mathrm{Mg} \mathrm{ha}^{-1}$ & Mg ha h ha-1 MJ-1 $\mathrm{mm}^{-1}$ \\
\hline 1 & $05 / 11 / 01$ & 82,8 & 1.104 & 9,16 & 0,008 \\
\hline 2 & $20 / 12 / 01$ & 63,1 & 841 & 6,78 & 0,008 \\
\hline 3 & $05 / 02 / 02$ & 90,8 & 1.210 & 12,60 & 0,010 \\
\hline 4 & $15 / 11 / 02$ & 60,8 & 811 & 6,03 & 0,007 \\
\hline 5 & $15 / 12 / 02$ & 92,2 & 1.229 & 16,74 & 0,014 \\
\hline 6 & $16 / 01 / 03$ & 99,9 & 1.332 & 20,25 & 0,015 \\
\hline 7 & $12 / 11 / 03$ & 85,3 & 1.137 & 10,06 & 0,009 \\
\hline 8 & $13 / 12 / 03$ & 83,2 & 1.109 & 9,71 & 0,009 \\
\hline 9 & $12 / 01 / 04$ & 90,7 & 1.209 & 13,66 & 0,011 \\
\hline 10 & $13 / 02 / 04$ & 93,8 & 1.250 & 18,26 & 0,015 \\
\hline 11 & $14 / 03 / 04$ & 96,0 & 1.280 & 19,21 & 0,015 \\
\hline M & - & 85,3 & 1.138 & 12,95 & 0,011 \\
\hline $\mathrm{DP}$ & - & 12,1 & 169 & 5,00 & 0,003 \\
\hline $\mathrm{CV}(\%)$ & - & 14 & 15 & 39 & 29 \\
\hline LI & - & 77,2 & 1.024 & 9,60 & 0,009 \\
\hline $\mathrm{LS}$ & - & 93,4 & 1.251 & 16,30 & 0,013 \\
\hline
\end{tabular}

M: média; DP: desvio-padrão; CV: coeficiente de variação; LI e LS: limites inferior e superior em relação à média no intervalo de confiança de $95 \%$. 
$\mathrm{mm}^{-1} \mathrm{e}$, conceitualmente, significa que cada unidade de erosividade da chuva (MJ $\mathrm{mm} \mathrm{ha}^{-1} \mathrm{~h}^{-1}$ ) ocasionou perda de solo de $0,011 \mathrm{Mg}^{-1}$, na média das chuvas. Nos testes de chuva simulada de números $3,7,8$ e 9 , os valores do fator $\mathrm{K}$ foram iguais ao da média, enquanto nos demais testes o fator $\mathrm{K}$ apresentou valores distintos do valor médio, levando-se em conta o intervalo de confiança de $95 \%$. Com base nesse intervalo, os limites inferior e superior para o fator $\mathrm{K}$ foram, respectivamente, de 0,009 e 0,013.

$\mathrm{O}$ valor do fator $\mathrm{K}$ calculado para o Nitossolo situouse entre os encontrados para alguns outros solos, ou seja, levemente maior do que 0,009 para um Latossolo (Martins Filho \& Pereira, 1993) e 0,008 para o outro (Jacobs et al., 1994). Este valor foi levemente menor do que 0,013 e 0,016, obtidos para um Cambissolo, respectivamente, por Bertol (1994) e Schick (1999) e essencialmente igual a 0,011 , encontrado por Bertol et al. (2002) para este mesmo Cambissolo. As semelhanças entre esses valores de fator $\mathrm{K}$, apesar de se referirem a distintos solos, podem ser devidas a fatores como: agente erosivo empregado (chuva natural ou chuva simulada), forma como o solo foi manejado antes de ser submetido ao agente erosivo e intervalo de tempo entre operações de preparo, variabilidade climática que influenciou a erosividade das chuvas (para o caso de chuva natural), esquema de aplicação de chuvas (para o caso de chuva simulada), entre outros. O valor de 0,011 do fator $\mathrm{K}$ foi, no entanto, expressivamente menor do que 0,021 , determinado por Denardin \& Wünsche (1980) para um Latossolo; entre 0,021 e 0,028 para outro Latossolo, estabelecidos por Martins Filho \& Silva (1985); e 0,033 para um Argissolo, determinado por Marques et al. (1997). Também aqui cabe a observação, em especial para o caso dos Latossolos, de que a forma de obtenção dos dados e a condição dos solos sob as quais eles foram obtidos, provavelmente, foram os principais fatores que determinaram as diferenças nos valores. Especialmente, em relação aos Latossolos, seria de se esperar que o fator $\mathrm{K}$ fosse maior no Nitossolo, pelo fato de este apresentar horizonte B textural, mais impeditivo à infiltração da água no solo do que o $\mathrm{B}$ latossólico dos Latossolos, além de apresentar perfil menos profundo do que deste. Comparando o fator $\mathrm{K}$ de 0,011 do Nitossolo ao de 0,033 do Argissolo, a diferença de três vezes se explica porque este apresenta horizonte A mais arenoso e horizonte B mais argiloso do que o primeiro, o que o torna naturalmente mais suscetível à erosão hídrica. Em razão disso, e obedecendo à lógica, o fator $\mathrm{K}$ do Nitossolo foi 5,5 vezes maior do que o valor de 0,002 , determinado por Marques et al. (1997) para um Latossolo.

A dispersão de pontos, observada na relação entre os valores de perda de solo e de erosividade das chuvas, foi relativamente pequena (Figura 1), o que pode ser comprovado pelo valor do coeficiente de determinação relativamente alto $\left(R^{2}=0,79\right)$, diferindo das relações obtidas por Bertol (1994), Silva et al. (1997), Marques et al. (1997), Schick (1999), Beutler (2000) e Bertol et al. (2002), em trabalhos realizados sob chuva natural, nos quais a dispersão dos pontos foi maior e os valores de $\mathrm{R}^{2}$, menores. Essa diferença é normal e decorre, provavelmente, do fato de que, neste trabalho, ocorreu melhor controle das variáveis que influenciaram a erosão hídrica, como teor de água do solo antecedente às chuvas e erosividade das chuvas, em razão de o experimento ter sido realizado sob chuva simulada. A distribuição de pontos na figura 1 mostra que a variação de perda de solo foi pequena com a variação de erosividade da chuva, tanto para baixos quanto para altos valores de erosividade. Isso pode ser parcialmente explicado pelas condições de relativa uniformidade, principalmente quanto ao teor de água do solo antecedente à aplicação dos testes de chuva simulada (Quadro 2). Assim, algumas chuvas, de baixa erosividade, levaram a baixas perdas de solo, enquanto outras, de alta erosividade, ocasionaram altas perdas. Ainda, maior número de chuvas simuladas, de alta erosividade, ocasionou maiores perdas de solo. Por sua vez, um menor número delas, de baixa erosividade, provocou menores perdas de solo, indicando que, possivelmente, o teor de água do solo antecedente às chuvas simuladas e os demais atributos do solo influenciaram as perdas de maneira semelhante em todos os testes de chuva.

$\mathrm{O}$ valor do fator erodibilidade do solo, estimado por meio de regressão linear simples, foi de 0,012 $\mathrm{Mg}$ ha h ha ${ }^{-1} \mathrm{MJ}^{-1} \mathrm{~mm}^{-1}$, como indicado pelo coeficiente de regressão, o qual, conceitualmente, significa a variação de perda de solo por unidade de variação de erosividade da chuva. Esse valor estimado do fator K foi diferente do encontrado por Bertol (1994) e Bertol et al. (2002), sob chuva natural, por este mesmo método, para um Cambissolo Húmico, diferindo, também, dos valores obtidos para outros solos, por vários autores (Denardin \& Wünsche, 1980;

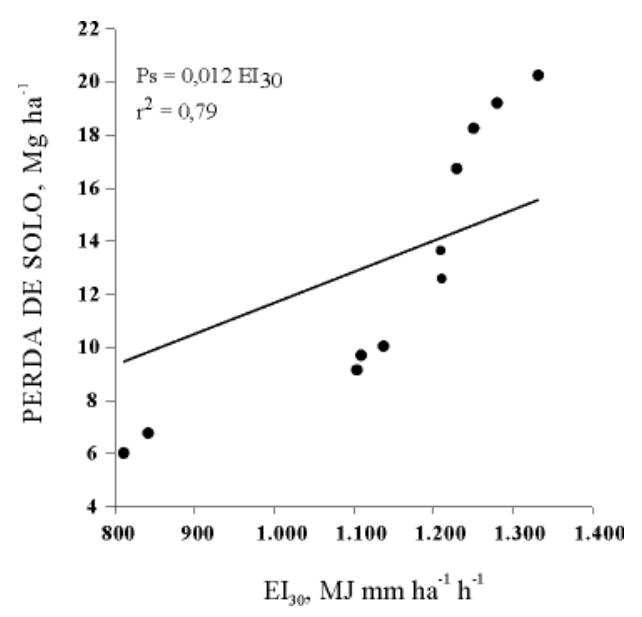

Figura 1. Relação das perdas de solo (PS) com a erosividade das chuvas simuladas aplicadas $\left(\mathrm{EI}_{30}\right)$ sobre um Nitossolo Háplico alumínico. A significância da relação está baseada no intervalo de confiança (IC) de $95 \%$. $\left(0,0097<\mathrm{IC}_{95}<0,0137\right)$. 
Martins Filho \& Silva, 1985; Marques et al., 1997; Beutler, 2000), os quais foram obtidos pela razão entre as perdas de solo e a erosividade das chuvas. Essas diferenças nos valores de fator $\mathrm{K}$ são normais e decorrem das diferenças nos tipos de solo e nos métodos de obtenção e de cálculo do referido fator.

Comparando-se o valor do fator erodibilidade calculado $\left(0,011 \mathrm{Mg}\right.$ ha h ha $\left.{ }^{-1} \mathrm{MJ}^{-1} \mathrm{~mm}^{-1}\right)$, visto no quadro 3 , com aquele estimado $(0,012 \mathrm{Mg}$ ha h ha-1 $\mathrm{MJ}^{-1} \mathrm{~mm}^{-1}$ ), encontrado na figura 1 , observa-se que a erodibilidade estimada por regressão linear simples foi $9 \%$ maior que aquela calculada pela razão entre as perdas de solo e a erosividade das chuvas. Mesmo assim, o valor da erodibilidade calculada $(0,011)$ situouse dentro do intervalo de confiança de $95 \%$ em relação ao valor da erodibilidade estimada $(0,012)$. A erodibilidade estimada por meio da regressão linear, representada pelo coeficiente angular $(0,012)$, situase no intervalo dos valores extremos 0,0097 e 0,0137, no intervalo de confiança de $95 \%$. A diferença de valores do fator $\mathrm{K}$ obtidos pelos dois métodos (determinado por cálculo e estimado por regressão) foi menor do que a encontrada por Bertol et al. (2002) para um Cambissolo Húmico, sob chuva natural, em cujo trabalho os autores utilizaram dados anuais de perdas de solo e de erosividade das chuvas.

\section{CONCLUSÕES}

1. As características fundamentais das chuvas simuladas aplicadas variaram temporalmente, em especial a altura e duração destas, enquanto os parâmetros de enxurrada relativos aos tempos de início e de pico, bem como o teor de água do solo antecedente às chuvas simuladas, pouco variaram; as perdas de solo, por sua vez, variaram expressivamente de uma chuva para outra, em conformidade com a variabilidade temporal da erosividade das chuvas simuladas, ocasionando, conseqüentemente, grande variabilidade temporal no fator de erodibilidade.

2. O valor do fator erodibilidade (fator K da EUPS) do Nitossolo Háplico alumínico, calculado pela razão entre os valores de perda de solo e os de erosividade das chuvas, foi de $0,011 \mathrm{Mg}$ ha h ha-1 $\mathrm{MJ}^{-1} \mathrm{~mm}^{-1}$. Quando estimado por regressão linear simples entre as perdas de solo e a erosividade das chuvas, o referido fator foi de 0,012 $\mathrm{Mg}$ ha h ha-1 $\mathrm{MJ}^{-1} \mathrm{~mm}^{-1}$, com dispersão relativamente baixa dos pontos.

\section{AGRADECIMENTOS}

Aos bolsistas de Iniciação Científica Fabrício Tondello Barbosa, Sidinei Roberto Ritter, Leonardo Felipe Brignoni, Wilson Antonio Zoldan Junior e André Júlio do Amaral, pelo auxílio na coleta dos dados no campo e tratamento destes em laboratório.

\section{LITERATURA CITADA}

BERTOL, I. Erodibilidade de um Cambissolo Húmico distrófico determinada sob chuva natural: Primeira aproximação. R. Bras. Ci. Solo, 18:335-338, 1994.

BERTOL, I.; MELLO, E.L.; COGO, N.P.; VÁZQUEZ VIDAL, E. \& GONZÁLEZ PAZ, A. Parâmetros relacionados com a erosão hídrica sob taxa constante de enxurrada, em diferentes métodos de preparo do solo. R. Bras. Ci. Solo, 30:715-722, 2006.

BERTOL, I.; SCHICK, J.; BATISTELA, O.; LEITE, D. \& AMARAL, A.J. Erodibilidade de um Cambissolo Húmico alumínico léptico, determinada sob chuva natural entre 1989 e 1998 em Lages (SC). R. Bras. Ci. Solo, 26:465-471, 2002 .

BEUTLER, J.F. Erosão hídrica num Latossolo Vermelho aluminoférrico submetido a diferentes sistemas de preparo e cultivo do solo. Lages, Universidade do Estado de Santa Catarina, 2000. 105p. (Tese de Mestrado)

CARVAlho, M.P. \& HERNANI, L.C. Parâmetros de erosividade da chuva e da enxurrada correlacionados com perdas de solo e erodibilidade de um Latossolo Roxo de Dourados (MS). R. Bras. Ci. Solo, 25:137-146, 2001.

CARVAlHo, M.P.; CATANEO, A. \& LOMBARDI NETO, F. Parâmetros de erosividade da chuva e da enxurrada correlacionados com as perdas de solo e determinação da erodibilidade de um Podzólico Vermelho-Amarelo de Pindorama. R. Bras. Ci. Solo, 21:279-286, 1997.

COGO, N.P. Effect of residue cover, tillage induced roughness, and slope length on erosion and related parameters. West Lafayette, Purdue University, 1981. 346p. (Tese de Doutorado)

DENARDIN, J.E. \& WÜNSCHE, W.A. Erodibilidade de um Latossolo Vermelho-Escuro. In: ENCONTRO NACIONAL DE PESQUISA SOBRE CONSERVAC̄̃O DO SOLO, 3., Recife, 1981. Anais. Recife, Universidade Federal Rural de Pernambuco, 1980. p.219.

FOSTER, G.R.; McCOOL, D.K.; RENARD, K.E. \& MOLDENHAUER, W.C. Conversion of the universal soil loss equation to SI metric units. Soil Water Conserv., 36:355-359, 1981.

HUDSON, N.W. Soil conservation. 3.ed. Ithaca, Cornell University Press, 1995. 324p.

JACOBS, G.A.; ROLOFF, G.; BISCAIA, R.C.M. \& MERTEN, G. Erosividade da chuva correlacionada com perdas de solo de dois Latossolos Vermelho-Escuro (texturas argilosa e média): uma aproximação do fator erodibilidade do solo. In: REUNIÃO BRASILEIRA DE MANEJO E CONSERVAÇ̃̃O DO SOLO E DA ÁGUA, 10.; Florianópolis, 1994. Resumos. Florianópolis, Sociedade Brasileira de Ciência do Solo, 1994. p.170-171.

LIEBENOW, A.M.; ELLIOT, W.J.; LAFLEN, J.N. \& KOHL, K.D. Interril erodibility: Collection and analysis of data from cropland soils. Trans. Am. Sci. Agric. Eng., 33:1882$1888,1990$.

MARGOLIS, E.; SILVA, A.B. \& JACQUES, F.O. Determinação dos fatores da Equação Universal de Perda de Solo para as condições de Caruaru (PE). R. Bras. Ci. Solo, 9:165169,1985 
MARQUES, J.J.G.S.M.; ALVARENGA, R.C.; CURI, N.; SANTANA, D.P. \& SILVA, M.L.N. Índices de erosividade da chuva, perdas de solo e fator erodibilidade para dois solos da região dos cerrados - primeira aproximação. R. Bras. Ci. Solo, 21:427-434, 1997.

MARTINS FILHO, E.M.V. \& PEREIRA, V.P. Influência da compactação do solo nas perdas por erosão e na sua erodibilidade. Ci. Agron., 8:39-45, 1993.

MARTINS FILHO, E.M.V. \& SILVA, J.R.C. Comparação de métodos de avaliação da erodibilidade de um Latossolo Vermelho distrófico. R. Bras. Ci. Solo, 9:175-177, 1985.

MEYER, L.D. An investigation of methods for simulating rainfall on standard runoff plots and a study of the drop size, velocity, and kinetic energy of selected spray nozzles. West Lafayette, USDA-ARS-SWCRD-ESWMRB and Purdue University, 1958. 43p. (Special Report, 81)

MUTCHLER, C.K. \& CARTER, E.C. Soil erodibility variation during the year. Trans. Am. Sci. Agric. Eng., 26:1102$1108,1983$.

RÖMKENS, M.J.M.; ROTH, C.B. \& NELSON, D.W. Erodibility of selected clay subsoils in relation to physical and chemical properties. Soil Sci. Soc. Am. J., 41:954-960, 1977.

SCHICK, J. Erosão hídrica em Cambissolo Húmico álico submetido a diferentes sistemas de preparo e cultivo do solo. Lages, Universidade do Estado de Santa Catarina, 1999. 114p. (Tese de Mestrado)
SILVA, M.L.N.; FREITAS, P.L.; BLANCANEAUX, P.; CURI, N. \& LIMA, J.M. Relação entre parâmetros da chuva e perdas de solo e determinação da erodibilidade de um Latossolo Vermelho-Escuro em Goiânia (GO). R. Bras. Ci. Solo, 21:131-137, 1997.

SWANSON, N.P. Suggestions for the use of the rotatingboom field plot rainfall simulator to obtain data for application of the soil loss equation. S.l, FAO, University of Nebraska, 1975. 6p. (Relatório de Consultoria)

TÁVORA, M.R.P.; SILVA, J.R.C. \& MOREIRA, E.G.S. Erodibilidade de dois solos da região de Ibiapaba, Estado do Ceará. R. Bras. Ci. Solo, 9:59-62, 1985.

WAGNER, C.S. \& MASSAMBANI, O. Análise da relação intensidade da chuva-energia de Wischmeier \& Smith e sua aplicabilidade à região de São Paulo. R. Bras. Ci. Solo, 12:197-203, 1988.

WISCHMEIER, W.H. A rainfall erosion index for a universal soil loss equation. Soil Sci. Soc. Am. Proc., 23:246-249, 1959.

WISCHMEIER, W.H. \& MANNERING, J.V. Relation of soil properties to its erodibility. Proc. Soil Sci. Soc. Am., 33:131$137,1969$.

WISCHMEIER, W.H. \& SMITH, D.D. Predicting rainfall erosion losses: A guide to conservation planning. Washington, Departament of Agriculture, 1978. 58p. (Agriculture Handbook, 537)

WISCHMEIER, W.H. \& SMITH, D.D. Rainfall energy and its relationship to soil loss. Trans. Am. Geophys. Union, 39:285-291, 1958. 